\title{
Perspective
}

PERSPECTIVE Actualité en histoire de l'art

Comptes rendus | 2010

Pavel Kalina, Benedikt Ried a počátky zaalpské renesance [Benedikt Ried et le début de la Renaissance outre-Alpes], Prague, Academia, 2010

\section{Klára Benešovská}

\section{(2) OpenEdition}

Journals

Édition électronique

URL : http://journals.openedition.org/perspective/2965

DOI : $10.4000 /$ perspective. 2965

ISSN : 2269-7721

Éditeur

Institut national d'histoire de l'art

Référence électronique

Klára Benešovská, «Pavel Kalina, Benedikt Ried a počátky zaalpské renesance [Benedikt Ried et le début de la Renaissance outre-Alpes], Prague, Academia, 2010 ", Perspective [En ligne], Comptes rendus, mis en ligne le 09 août 2013, consulté le 01 octobre 2020. URL : http://journals.openedition.org/ perspective/2965 ; DOI : https://doi.org/10.4000/perspective.2965 
Pavel Kalina, Benedikt Ried a počátky zaalpské renesance [Benedikt Ried et le début de la Renaissance outre-Alpes], Prague, Academia, 2010

Klára Benešovská

\section{RÉFÉRENCE}

Pavel Kalina, Benedikt Ried a počátky zaalpské renesance [Benedikt Ried et le début de la Renaissance outre-Alpes], Prague, Academia, 2010. 
1 Pavel Kalina présente le résultat de sa recherche sur le personnage de l'architecte royal Benedikt Ried - fameux avant tout pour la salle Vladislav au Château de Prague (1492-1502)-, le replaçant dans le large contexte de son époque, en particulier celui de la Renaissance italienne. L'auteur aborde divers aspects de son œuvre : l'application de la géométrie, le dialogue entre naturalisme et symbolisme, la construction des voûtes, l'emploi des nouvelles technologies. Il s'intéresse aussi à la typologie des bâtiments, des résidences de Renaissance et de l'architecture défensive aux forteresses et aux cathédrales - tous des types qui figurent dans l'œuvre de Ried- et l'ouvrage comprend un catalogue des

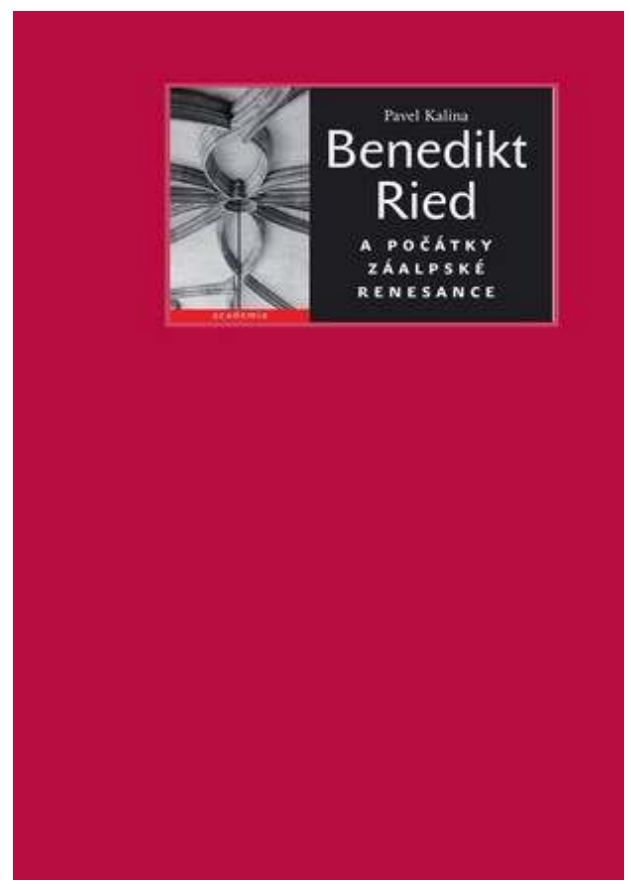
édifices concernés. Sont ainsi recensés le Château de Prague (avec son système de défense et son palais), la cathédrale Saint-Guy (construite dans la continuité du chantier pré-hussite), la maison de plaisance dans la forêt Stromovka (aujourd'hui à Prague), les châteaux de la haute noblesse Svihov, Rabi, Blatna et Zabkowice, la cathédrale Sainte-Barbe de Kutna hora, et les voûtes des églises de Most-Bruck, Annaberg et Louny (œuvres des élèves de Ried). La conclusion aborde la question du positionnement de l'architecte entre Gothique et Renaissance. Bien que le sens du livre provienne avant tout du texte, il est richement illustré, même si les clichés en noir et blanc sont relativement petits. 